\title{
RURAL MEDICAL EDUCATION: HELPING TO SOLVE THE RURAL WORKFORCE CRISIS
}

\author{
Mohamed Khadra \\ Greater Murray Clinical School \\ University of New South Wales, Wagga Wagga
}

There is a shortage of doctors in regional, rural and remote parts of Australia. The most immediate and sustainable increase in the rural medical workforce is likely to result from training doctors who are more likely to consider a rural career. Two key factors here are:

- increasing the numbers of students from rural backgrounds that gain entry to medical training;

- increasing the amount of exposure that undergraduate students have to rural settings.

This article describes the Greater Murray Clinical School, a school that provides a comprehensive medical education in a rural setting, which aids in the recruitment and retention of a rural medical workforce.

\section{BACKGROUND}

There is a shortage of doctors in regional, rural and remote parts of Australia. While around 30 per cent of the Australian population live outside the metropolitan areas, only 15.6 per cent of doctors practise there. ${ }^{1}$ There are 143.6 practising medical practitioners per 100,000 population in regional, rural and remote areas, compared with 306.3 per 100,000 population in metropolitan areas. ${ }^{1}$ The benchmark for an adequate supply of doctors, established by the Australian Workforce Medical Advisory Committee, is 250 per 100,000 of the population. ${ }^{2}$ The majority of doctors in regional, rural and remote areas are engaged in primary care (60.2 per cent), and shortages in specialists are even more pronounced. ${ }^{1}$ This shortage of doctors is reflected in decreased access to health care. For example, there are 26.4 per cent more general practitioner (GP) consultations per 1,000 persons in capital cities when compared with large country towns. ${ }^{3}$ The population per full-time equivalent GP in 199697 was 1,034 in capital cities compared to 2,781 in remote areas. ${ }^{3}$ Not only does the remote GP provide a service to more people, those people are more widely dispersed. The concentration of population per square kilometre is 331 in capital cities compared with 0.1 in remote areas.

\section{INCREASING THE RURAL MEDICAL WORKFORCE}

It is clear there is a need to increase the number of doctors in regional, rural and remote Australia. To achieve this, there are three options available:
- to attract doctors working in oversupplied areas to relocate;

- to increase the retention of doctors currently in rural practice;

- to train doctors that are more likely to consider a rural career.

The first two options are difficult to achieve in the short term.

The reasons that attract doctors to a rural career include:

- a perceived improved quality of life

- family ties

- more 'job satisfaction'

- availability of work. ${ }^{4}$

The reasons that cause doctors to leave rural practice include:

- overwork and burnout

- deskilling

- a partner desiring to return to the city

- the education of children.,6

Hays et al. advocate several strategies to improve retention of medical practitioners in rural areas including:

- locum relief

- flexible delivery of continuing medical education

- better-managed skills training

- improved housing quality

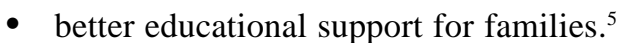

If these strategies are to be successful, then strategic planning is necessary.

The most sustainable increase in rural medical workforce will result from training doctors who are more likely to consider a rural career. The two key factors in achieving this goal are:

- increasing the number of medical students from a rural background or with significant rural connections (students from rural backgrounds being 2.5 times more likely to enter a rural career); ${ }^{4}$

- increasing the exposure of students to rural medicine during their undergraduate years. ${ }^{4}$

However, a rural student is less than half as likely to attain the required marks to enter medical school compared with an urban student. ${ }^{7}$ In addition, a rural student with the required marks is less likely to apply to do medicine. ${ }^{7}$ The lack of peer pressure, lower expectations, less experienced teachers, and a relative lack of resources in 
schools, may all be factors that play a part. This means that, proportional to the population, fewer students from a rural background gain entry to medicine. Of the first year cohort of medical students in 1999, only 11.4 per cent came from a rural or remote area. ${ }^{1}$

The Australian Medical Workforce Advisory Committee has recommended several measures to remedy this situation, including:

- the use of affirmative entry to medical school for rural high school students;

- the appointment of rural doctors to academic positions;

- exposure to rural health issues in the curriculum. ${ }^{2}$

Several universities in Australia are in the process of adopting these measures. For example, the University of Newcastle has had an affirmative action scheme for Aboriginal students in place for over 15 years. The University of New South Wales has had a Rural Student Entry Scheme operating since 1996, which has resulted in 21 per cent of the medical student intake in 2001 coming from a rural background.

It is important to increase a student's exposure to rural experiences. ${ }^{4}$ Australian data show that if a medical student is exposed to a rural experience in their final year they are three times more likely to chose a rural career. ${ }^{4}$ Data from overseas reflects similar findings. In 1971 the University of Washington decentralised its medical teaching to the rural states of Alaska, Montana, and Idaho. This redistribution of medical education throughout the region supports the hypothesis that simply increasing medical student numbers in urban Washington is not sufficient to address the maldistribution of doctors in rural areas. ${ }^{8}$ It is necessary to train students in the rural setting; and to develop a partnership between rural areas and urban centres of medical training. The redistribution of medical education in Washington, along with other examples of similar redistributions in New Mexico and Canada, have shown that students who spend a substantial part of their undergraduate experience in a rural setting are much more likely to chose a rural career. ${ }^{9}$

\section{THE ESTABLISHMENT OF THE GREATER MURRAY CLINICAL SCHOOL}

The Greater Murray Clinical School is an initiative of the Commonwealth Department of Education, Training and Youth Affairs; the University of New South Wales; and the Greater Murray Area Health Service. The School, which is based in south west NSW and north east Victoria, has campuses in Wagga Wagga, Albury, Wodonga and Griffith. The aim of the School is to provide comprehensive educational opportunities for students in a rural setting, with the objective of assisting in the recruitment and retention of doctors to these areas. The
School was launched in February 2000 and has developed rapidly. Recently, the School has expanded to include the Mid North Coast and parts of the Illawarra, and it is now part of a network of new rural clinical schools and university departments of rural health in other parts of Australia.

The characteristics that determine the success of rural clinical schools are:

- their entire budget is spent in the rural and remote areas;

- the curriculum is deliverable by rural practitioners without excessive demands on their time;

- the curriculum should address both rural and indigenous issues;

- $\quad$ substantial numbers of students (at least 25 per cent) should spend a substantial part of their clinical years in the rural setting (at least 50 per cent).

It costs more to train a rural medical student than their urban counterpart. Rural area health services have not been funded for medical education. Libraries, information technology and educational infrastructure need to be upgraded, or in some cases created. One of the key technologies that need to be established is videoconferencing. This allows interactive educational sessions with students on placement in remote towns. Using a combination of videoconferencing and Web-based resources allows almost the entire clinical curriculum to be delivered independent of other resources present in the remote centre.

A major challenge in this regard is that videoconferencing costs are charged by distance. Telstra, for example, charges a call made between two centres $50 \mathrm{~km}$ apart at rates substantially more than those charged for calls made within a capital city $(<25 \mathrm{~km})$. This distance-based pricing policy limits access to videoconferencing technology in rural areas and creates a disadvantage for rural communities.

\section{THE COMMUNITY-BASED MEDICAL CURRICULUM}

Choice of curriculum is paramount. It is vital that the medical curriculum is deliverable in the rural setting and is not onerous for local doctors to teach. The patientcentred, longitudinal model developed by the Greater Murray Clinical School is a community-based model where student learning is directed by the patients they see. The students are introduced to the patient by the general practitioner, emergency medicine physician or other specialist. The student then follows the patient throughout their illness. Wherever the patient interacts with the health care system, the student attends. At each contact the health care professional (doctor, nurse or allied health professional) is encouraged to identify learning 


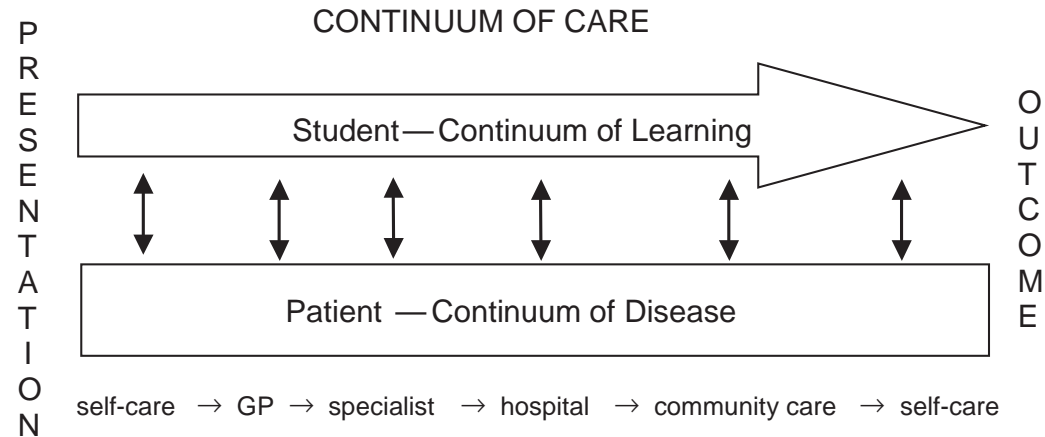

issues for the student relevant to their patient. No expectation exists to give a didactic dissertation on the disease. The student's responsibility is to follow up these learning issues in private study using the Web and other resources provided by the School. A substantial period of time is spent in indigenous health facilities. Apart from providing an anchor for knowledge, a relationship develops between student and patient that fosters a deeper understanding of emotional, psychological, social, community and economic effects of the disease.

A key component of the model is the so called 'integration tutorial' which is held once a week in which a tutor reviews the student experiences. The model avoids making demands on local practitioners by utilising the 'fly on the wall' approach where students sit in with doctors in their surgery. Students are assessed in the same way as their urban colleagues.

The approach at the University of New South Wales is that at least a quarter of the intake will spend half of their clinical years (the final three years) training in a rural setting. Students are given an opportunity to spend longer periods if they so desire. The idea is that students immerse themselves in the rural environment and hence make connections with the community and the setting.

\section{CONCLUSION}

Rural medical education is in its infancy, and the first measures of success in terms of recruiting doctors into rural careers will not be known for 5-10 years. However, the presence of the Greater Murray Clinical School has attracted several practitioners to rural areas, and the School runs a large research stream and facilitates a comprehensive program of continuing medical education. The benefits of providing a diverse medical education in a rural setting will certainly assist in the recruitment and retention of a rural medical workforce.

\section{REFERENCES}

1. Australian Medical Workforce Advisory Committee. The Annual Report 1999-2000. Canberra: Australian Institute of Health and Welfare, 2000.

2. Australian Medical Workforce Advisory Committee. The Medical Workforce in Rural and Remote Australia. Canberra: Australian Institute of Health and Welfare, 1996.

3. Australian Medical Workforce Advisory Committee. Medical Workforce Supply and Demand in Australia: A Discussion Paper. Vol. HWL 12. Canberra: Australian Institute of Health and Welfare, 1998.

4. Rolfe I, Pearson S, O'Connell D, and Dickinson J. Finding solutions to the rural doctor shortage: the roles of selection versus undergraduate medical education at Newcastle. Med $J$ Aust 1995; 25: 512-517.

5. Hays R, Veitch P, Cheers B, and Crossland L. Why doctors leave rural practice. Australian Journal of Rural Health 1997; 5: 198-203.

6. Kamien M. Staying in or leaving rural practice: 1996 outcomes of rural doctor's 1986 intentions. Med J Aust 1998; 169: 318321.

7. Kamien M and Butterfield I. Some solutions to the shortage of general practitioners in rural Australia. Part 1. Medical School Selection. Med J Aust 1991; 153: 105-107.

8. Adkins R, Anderson G, Cullen T, Myers W, Newman F, and Schwarz M. Geographic and specialty distributions of WAMI program participants and nonparticipants. Journal of Medical Education 1987; 62: 810-817.

9. Worley P, Prideaux D, Strasser R, Silagy C, and Magarey J. Why we should teach undergraduate medical students in rural communities. Med J Aust 2000; 172: 615-616. 战 